\title{
Identification of Two Mutations in Human Xanthine Dehydrogenase Gene Responsible for Classical Type I Xanthinuria
}

\author{
Kimiyoshi Ichida, ${ }^{\star}$ Yoshihiro Amaya, ${ }^{\ddagger}$ Naoyuki Kamatani, ${ }^{\S}$ Takeshi Nishino, $\|$ Tatsuo Hosoya, ${ }^{*}$ and Osamu Sakai \\ *Second Department of Medicine, The Jikei University School of Medicine, Tokyo 105; ${ }^{\ddagger}$ Department of Biochemistry, Yokohama City \\ University School of Medicine, Yokohama 236, Japan; ${ }^{\S}$ Institute of Rheumatology, Tokyo Women's Medical College, Tokyo 162; and \\ "Department of Biochemistry and Molecular Biology, Nippon Medical School, Tokyo 113, Japan
}

\begin{abstract}
Hereditary xanthinuria is classified into three categories. Classical xanthinuria type I lacks only xanthine dehydrogenase activity, while type II and molybdenum cofactor deficiency also lack one or two additional enzyme activities. In the present study, we examined four individuals with classical xanthinuria to discover the cause of the enzyme deficiency at the molecular level. One subject had a $\mathrm{C}$ to $\mathrm{T}$ base substitution at nucleotide 682 that should cause a CGA (Arg) to TGA (Ter) nonsense substitution at codon 228. The duodenal mucosa from the subject had no xanthine dehydrogenase protein while the mRNA level was not reduced. The two subjects who were siblings with type I xanthinuria were homozygous concerning this mutation, while another subject was found to contain the same mutation in a heterozygous state. The last subject who was also with type I xanthinuria had a deletion of $\mathrm{C}$ at nucleotide 2567 in cDNA that should generate a termination codon from nucleotide 2783. This subject was homozygous for the mutation and the level of mRNA in the duodenal mucosa from the subject was not reduced. Thus, in three subjects with type I xanthinuria, the primary genetic defects were confirmed to be in the xanthine dehydrogenase gene. (J. Clin. Invest. 1997. 99: 2391-2397.) Key words: urolithiasis - aldehyde oxidase • sulfite oxidase $\bullet$ molybdenum cofactor $\bullet$ hypouricemia
\end{abstract}

\section{Introduction}

Human xanthine dehydrogenase (EC 1.1.1.204) catalyzes the terminal two steps of the purine degradation pathway; i.e., the formation of xanthine from hypoxanthine and uric acid from xanthine. Under certain conditions, xanthine dehydrogenase is converted to the oxidase form, known as xanthine oxidase (EC 1.2.3.2). This enzyme has been a focus of extensive studies since $(a)$ it is the target of action of a widely used antihyperuricemic drug, allopurinol; $(b)$ it may be responsible for the production of superoxide radicals, which are putative pathological compounds in various disorders in humans; $(c)$ inherited enzyme deficiencies have been described in humans; and $(d)$ the

Address correspondence to Kimiyoshi Ichida, Second Department of Medicine, The Jikei University School of Medicine, Nishi-Shinbashi, Minato-ku, Tokyo 105, Japan. Phone: 81-3-3433-1111; FAX: 81-33433-4297.

Received for publication 11 November 1996 and accepted in revised form 28 February 1997.

J. Clin. Invest.

(C) The American Society for Clinical Investigation, Inc.

0021-9738/97/05/2391/07 \$2.00

Volume 99, Number 10, May 1997, 2391-2397 enzyme itself is a typical molybdenum containing flavo-protein.

Inherited xanthine dehydrogenase deficiency, or xanthinuria, was first reported by Dent and Philport (1). The current classification of this inherited disorder is rather complicated. In classical xanthinuria type I, only xanthine dehydrogenase activity is lacking, while in classical xanthinuria type II, aldehyde oxidase activity is also deficient $(2,3)$. More complicated still is the presence of molybdenum cofactor deficiency, in which sulfite oxidase activity is missing as well as the above two enzymes (4).

Classical xanthinuria types I and II are rare autosomal recessive disorders and the combined incidence has been reported to be $1 / 69,000$ (5). The affected individuals may develop urinary tract calculi, acute renal failure, or myositis due to tissue deposition of xanthine, but some subjects with homozygous xanthinuria remain asymptomatic (2). Molybdenum cofactor deficiency is usually associated with severe neurological disorders (4). The relationship between the three conditions has not been well understood at the molecular level, since precise molecular analyses have not been performed.

We recently cloned rat (6) and subsequently human (7) xanthine dehydrogenase cDNA and determined the primary structures. The human gene was mapped to chromosome $2 \mathrm{p} 22$ or 2p23 (8). Human aldehyde oxidase cDNA was also cloned and sequenced, although it was initially claimed as cDNA of xanthine dehydrogenase (9) and was subsequently found to be of aldehyde oxidase (10). As a first step to determine which gene is responsible for each xanthinuria type, we attempted to define mutations in the human xanthine dehydrogenase gene in patients with classical xanthinuria.

\section{Methods}

Subjects used in this study. Subjects 1 and 2 were brothers, 34 and 35 yr old, respectively, when examined. Their parents were first cousins. Subject 1 was first found to be hypouricemic during a routine health examination; he also had mild gastritis and a duodenal ulcer. Subject 2 was asymptomatic. Details on subject 3, a 65-yr-old male, and subject 4, a 37-yr-old male, have been reported previously in the Japanese literature $(11,12)$. The chronic renal failure of subject 3 had been attributed to diabetes mellitus (11). Subject 4 had a single kidney. The parents of subject 4 were not consanguineous, but their families had lived in the neighborhood for generations. As far as we traced, there was no familial relationship between subjects 3 and 4 and the parents of subjects 1 and 2. Duodenal mucosal tissues were obtained from subjects 1 and 4 and a control subject during endoscopic examinations. The mucosal tissues were frozen at $-80^{\circ} \mathrm{C}$ immediately after collection. The control subject from whom the duodenal mucosa sample and the peripheral blood cells were obtained was a healthy 36-yr-old male. Peripheral blood cells from five other healthy volunteers were used for isolating DNA as control samples. Liver tissue from a 58-yr-old male tumor patient was used for confirmation of the reactivity of the antiserum against rat xanthine dehy- 


\begin{tabular}{|c|c|c|c|}
\hline \multicolumn{2}{|l|}{ Forward } & \multicolumn{2}{|l|}{ Reverse } \\
\hline Sequence & Position* & Sequence & Position* \\
\hline $\begin{array}{c}\text { Comp20 GTGACAATGACAGCAGACAAACAAGTTT- } \\
\text { CGTGAGCTGATTG }\end{array}$ & & $\begin{array}{c}\text { Comp21 GTGGCTGACTGAGTGGTCATTTGATT- } \\
\text { CTGGACCATGGC }\end{array}$ & \\
\hline 20 GCGAATTCGTGACAATGACAGCAGACAAA & $-6-15$ & 21 AACTCGAGGTGGCTGACTGAGTGGTC & $573-556$ \\
\hline 64 GTCTCTTAGGAGTGAGG & $-49--33$ & 65 GTGGCTGACTGAGTGGTC & $573-556$ \\
\hline 22 AACTCGAGGATGGTGGATGCTGTGGA & $496-513$ & 13 CACTGGCCATGAACACG & $1105-1089$ \\
\hline P4 GCGCTGGTTTGCTGGGAAGC & $1002-1021$ & 6 GATGCAGCTCCTCTGCC & $1486-1470$ \\
\hline 17 TCAGCCCTCAAGACCAC & $1393-1409$ & 27 GCCTCGAGGATATGCCCAACACAAGT & 2001-1984 \\
\hline 49 CCCAAGGGTCAGTCTGAG & $1693-1710$ & 50 AATCCGGTTTGCTGGAAC & $2364-2347$ \\
\hline 28 CAGAATTCGCGAAGGATAAGGTTACT & $1968-1986$ & 5 TCCAGCATGCATCGCAC & $2486-2470$ \\
\hline 1 GAGCACTTCTACCTGGA & $2221-2237$ & 10 TAGCAGTTGTCCATGTG & $2669-2653$ \\
\hline 30 CGGAATTCGCCCTGGCTGCATATAAG & $2440-2457$ & 31 TTCTCGAGCTTGTCAACCTCACTCTT & $2961-2944$ \\
\hline 55 GAAGTTGCAGTGACCTGT & $2788-2805$ & 33 TTCTCGAGGTTAGTCTCAAAGCTGTA & $3438-3421$ \\
\hline 34 TGGAATTCTGCCACTGGGTTTTATAG & $3385-3404$ & 35 AGCTCGAGCTGCACGGATGG & $3852-3833$ \\
\hline 42 TTTGTCCAGGGCCTTGG & $3598-3614$ & 66 AAGACTCTGCTGAGGAC & $4026-4010$ \\
\hline
\end{tabular}

Primers Comp20, Comp21, 20, and 21 were used for competitive RT-PCR. *Nucleotide residue numbers are according to Ichida et al. (7).

drogenase to human enzyme after hepatectomy. Informed consents for various procedures were obtained from all subjects at the outset of the study.

Determination of compounds in serum and urine. Concentrations of hypoxanthine, xanthine, and uric acid in both serum and urine, and concentrations of oxypurinol in serum were determined by the HPLC method, as described earlier (13).

Xanthine dehydrogenase/oxidase assay. Xanthine dehydrogenase/ oxidase activity was determined by the HPLC method (13) in the laboratory of Dr. Toshihiro Nishina in Toranomon Hospital.

Allopurinol loading test. Three allopurinol tablets (100 mg each) were administered after overnight fasting to each subject and the concentration of oxypurinol was determined in the serum from a blood sample obtained $1 \mathrm{~h}$ after the administration of the drug.

Establishment of B lymphoblast cell lines. Genomic DNA was isolated from peripheral blood cells using a QIAGEN blood and cell culture DNA kit (Qiagen, Hilden, Germany). B lymphoblast cell lines were established from subjects 3 and 4 using Epstein-Barr virus transformation.

Western blotting. The frozen duodenal mucosal tissues were thawed before the experiments and homogenized in $5 \mathrm{vol}$ of $100 \mathrm{mM}$ potassium phosphate buffer, $\mathrm{pH} 7.4$, containing $1 \mathrm{mM}$ PMSF (Wako, Osaka, Japan), $0.02 \mathrm{mg} / \mathrm{ml}$ each of aprotinin (Miles Inc., Kankakee, IL), chymostatin (Peptide Laboratory, Osaka, Japan), pepstatin (Peptide Laboratory) and antipain (Peptide Laboratory), and $0.1 \mathrm{mg} / \mathrm{ml}$ of leupeptin (Peptide Laboratory), by a Potter-Elvehjem homogenizer at $4^{\circ} \mathrm{C}$. The homogenates were centrifuged for $1 \mathrm{~h}$ at 100,000 $\mathrm{g}$. The supernatants $(20 \mu \mathrm{g})$ were subjected to gradient SDS polyacrylamide gel electrophoresis in which the concentration of polyacrylamide was varied from 4 to $20 \%$. After electrophoresis, the protein was transblotted from the gel onto a membrane (Clear Blot Membrane-P; Atto, Tokyo, Japan) using a semidry transblot apparatus (Atto). The bands for xanthine dehydrogenase were made visible using rabbit antiserum raised against rat xanthine dehydrogenase and a Vectastain ABC alkaline phosphatase kit (Vector Laboratories, Inc., Burlingame, CA), essentially according to the supplier's protocol. As the antiserum against rat enzyme was known to react with rat enzyme to form precipitate (14), the same antiserum was confirmed to react also with human enzyme by determination of enzyme activity of the supernatant obtained by addition of the antiserum to the human liver extract followed by centrifugation (data not shown).
Quantification of $m R N A$ for xanthine dehydrogenase using competitive reverse transcriptase-PCR. Total RNA was isolated from duodenal mucosae or B lymphoblasts using Isogen (Nippon Gene, Tokyo, Japan) according to the manufacturer's recommendations. Xanthine dehydrogenase mRNA in the samples was quantified by competitive reverse transcriptase (RT) ${ }^{1}$-PCR using a MIMIC construction kit (Clontech, Palo Alto, CA). The competitive template was constructed from $2 \mathrm{ng}$ of Bam HI/Eco RI fragment of v-erbB using primers Comp20 and Comp21 (Table I) in the first 16-cycle PCR at $94^{\circ} \mathrm{C}, 45 \mathrm{~s} ; 60^{\circ} \mathrm{C}, 45 \mathrm{~s}$; and $72^{\circ} \mathrm{C}, 90 \mathrm{~s}$. After the RT reaction using RNA from the mucosae, the competitive PCR was performed. Thus, the solution containing cDNA of xanthine dehydrogenase synthesized by the RT reaction was mixed with various concentrations of the competitive template, and 18 cycles of PCR reactions were performed using primers 20 and 21 (Table I).

Direct sequencing of cDNA. The primers used for RT-PCR amplification of cDNA of human xanthine dehydrogenase are shown in Table I. cDNA was reverse transcribed from total RNA from the duodenal mucosae or B lymphoblasts and subjected to the PCR reactions. The conditions for PCR were essentially the same as previously described (15) with an annealing temperature of $62^{\circ} \mathrm{C}$. The PCR products were separated by agarose gel electrophoresis, cut out from the gel, and isolated using GeneClean kit (BIO 101, La Jolla, CA). Direct sequencing was performed using a Dye Terminator Cycle Sequencing Kit and an automated sequencer (ABI Imaging Inc., Anaheim, CA).

Direct sequencing of DNA. The amplification of genomic DNA for the analysis of the nucleotide change at nucleotide 2567 was performed by PCR using the following two primers: 30 (sense primer, Table I) and ACTCTGAGAGAGATCCT (antisense primer). These primers amplify an $\sim 2$-kbp sequence of genomic DNA including the point of deletion mutation at nucleotide 2567 found in subject 4 . The nucleotide numbers in this paper always indicate those in cDNA but not in genomic DNA. When those numbers are used for genomic DNA, they indicate the nucleotide positions corresponding to such nucleotide positions in cDNA sequences. The amplified genomic DNA was sequenced by the direct sequencing method.

1. Abbreviations used in this paper: SSCP, single-stranded conformation polymorphism; RT, reverse transcriptase. 
The amplification of genomic DNA for the analysis of the nucleotide substitution at nucleotide 3449 was performed by PCR using the following two primers: AACACCCAATCTGGGCTACA (sense primer) and CTTATGATCTCCTGTTAGGC (antisense primer). These primers amplify a 115 -bp sequence of genomic DNA including the base substitution at nucleotide 3449 . Whether the nucleotide at position 3449 was $\mathrm{C}$ or $\mathrm{G}$ could be determined by both the direct sequencing and the digestion of the amplified genomic DNA with Aci I. When the nucleotide position at 3449 is G, the amplified DNA should be digested with Aci I into two fragments, while when it is $\mathrm{C}$, the DNA should be resistant to the digestion.

Single-stranded conformation polymorphism analysis after PCR amplification of genomic DNA. For the detection of the nucleotide change at the position of 682, a part of the genomic xanthine dehydrogenase gene was amplified by PCR using the following two primers: AGACACTCCTCGGAAGCAGC (sense primer) and CGTGTTCCCCACGACCAGCT (antisense primer). These primers amplify a 127-bp sequence of xanthine dehydrogenase genomic DNA, including the nonsense base substitution found in subject 1 . Then the amplified DNA was subjected to the single-stranded conformation polymorphism (SSCP) analysis according to the previous methods, except for the temperature during the electrophoresis. In the present experiment, the electrophoresis was performed at $37^{\circ} \mathrm{C}$. After the electrophoresis, the gel was stained with silver as described previously (16).

\section{Results}

Clinical tests. The basis of the hypouricemia in subjects 1 and 2 was sought. Both were found to excrete excessive amounts of xanthine and hypoxanthine (Table II) and their conditions were diagnosed as xanthinuria. The classification of classical xanthinuria is determined by the outcome of an allopurinol loading test (3). Since aldehyde oxidase as well as xanthine dehydrogenase converts allopurinol to oxypurinol, type II but not type I xanthinuria patients lack the ability to produce oxypurinol from allopurinol (3). Since oxypurinol was detected after the allopurinol loading test in both subjects 1 and 2 (Table II), they were classified as classical xanthinuria type I.

Although precise clinical data on subjects 3 and 4 have already been published $(11,12)$, we include some of them in Table II since the previous papers were in Japanese. Table II indicates that subject 3 had xanthinuria, but it is not clear whether he should be classified as type I or II since there was no allopurinol loading test. Unfortunately, we were unable to contact him directly, so the classification of his xanthinuria is not possible. The renal function of subject 3 was severely impaired, which was attributed to diabetes mellitus but not to xanthinuria (11). Although data on the allopurinol loading test on subject 4 were not included in the previous paper (12), we performed the test on the subject and found that he had type I xanthinuria (Table II).

Detection of xanthine dehydrogenase protein in duodenal mucosa. The duodenal mucosa samples (from subject 1 and the control subject) were submitted to Western blot analysis, as described in Methods. A clear band corresponding to human xanthine dehydrogenase was detected at $150 \mathrm{kD}$ for the control sample while no such band was observed for the sample from subject 1 (Fig. 1). The bands at 127 and $50 \mathrm{kD}$ in Fig. 1 were considered to be nonspecific bands because neither the reported size of the native form of xanthine dehydrogenase nor those of the proteolytic products were 127 or $50 \mathrm{kD}$ (17). However, a possibility that either of these bands corresponds to the truncated mutational peptide cannot be completely excluded.

Quantitation of $m R N A$ for xanthine dehydrogenase. Total RNA was separated from the duodenal mucosa samples, after which the RNA samples were subjected to the competitive RT-PCR procedure, as described in Methods. While the primers 20 and 21 should amplify a 579-bp fragment of human xanthine dehydrogenase cDNA, the same primers are expected to amplify a 441-bp fragment from a competitor template. By comparing the concentrations of the competitor template that gave nearly equal fluorescent intensities of the amplified 579and 441-bp fragments between subject 1 and the control samples, we could compare the amounts of mRNA for xanthine dehydrogenase between the control subject and subject 1 . For both subject 1 and the control, the fluorescent intensities for 579- and 441-bp fragments were nearly equal at a competitor fragment concentration of $5.0 \times 10^{-3}$ amol competitor/tube (Fig. 2). Virtually identical results were obtained in separate experiments where different amounts of total RNA or different PCR cycles were used (data not shown). These data indi-

Table II. Clinical Data from Four Xanthinuria Subjects and a Control Subject

\begin{tabular}{|c|c|c|c|c|c|c|}
\hline Subject & & 1 & 2 & $3^{*}$ & $4^{\ddagger}$ & Control \\
\hline Sex & & Male & Male & Male & Male & Male \\
\hline Age & (yr) & 34 & 35 & 65 & 37 & 36 \\
\hline Creatinine clearance & $(\mathrm{ml} / \mathrm{min})$ & 129 & 138 & 8.6 & 1.3 & 121 \\
\hline Serum urate & $(\mathrm{mg} / \mathrm{dl})$ & 0.1 & 0.4 & 0.1 & 0.1 & 6.8 \\
\hline Urate clearance & $(\mathrm{ml} / \mathrm{min})$ & 1.13 & 0.17 & NM & 0.06 & 10.2 \\
\hline Uric acid/creatinine in urine & $(\mu \mathrm{mol} / \mathrm{mmol})$ & 1 & 0.6 & 4 & 0.2 & 382 \\
\hline Serum hypoxanthine & $(\mu \mathrm{M})$ & 5.9 & 7.3 & 0.8 & 1.6 & 6.2 \\
\hline Serum xanthine & $(\mu \mathrm{M})$ & 23.6 & 15.8 & 85 & 38.5 & 2.7 \\
\hline Hypoxanthine/creatinine in urine & $(\mu \mathrm{mol} / \mathrm{mmol})$ & 89 & 57.8 & 1.5 & 38.9 & 4.2 \\
\hline Xanthine/creatinine in urine & $(\mu \mathrm{mol} / \mathrm{mmol})$ & 110 & 85.7 & 132 & 108.2 & 3.6 \\
\hline Xanthine oxidase activity & (nmol/h per mg protein) & ND & ND & ND & ND & 52 \\
\hline Serum oxypurinol $^{\S}$ & $(\mu \mathrm{g} / \mathrm{ml})$ & 2.8 & 3.1 & NM & 0.61 & 2.3 \\
\hline Type of xanthinuria & & I & I & Unknown & I & - \\
\hline
\end{tabular}

ND, not detected; NM, not measured. *Clinical data for subject 3 were from reference $11 .{ }^{\star}$ Clinical data for subject 4 were from reference $12 .{ }^{\S}$ Serum oxypurinol was measured at $1 \mathrm{~h}$ after loading. 


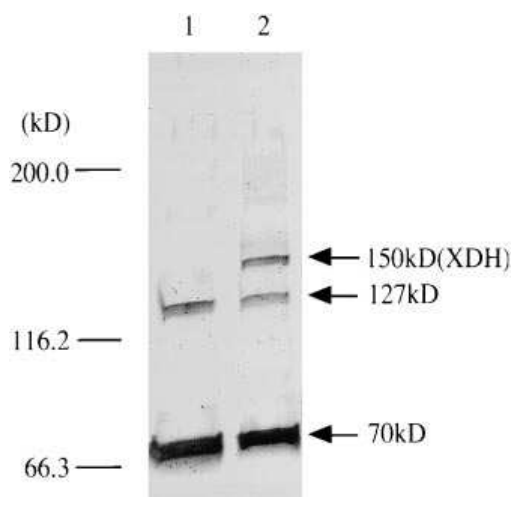

brane and immunostained with antiserum against rat xanthine dehydrogenase. Positions of molecular markers are shown at the left side of the panel. $150-\mathrm{kD}$ bands correspond to human xanthine dehydrogenase, while other bands are nonspecific.

cate that the xanthine dehydrogenase gene is indeed transcribed and retained in the cells of subject 1 . We subsequently performed an equivalent analysis on the duodenal mucosa sample from subject 4 . The amount of mRNA in the mucosa from subject 4 was not significantly different from the sample from the control subject (data not shown).

Direct sequencing of $c D N A$. Since mRNA was confirmed to be present in the cells of subjects 1 and 4, we amplified and sequenced all the coding regions of the xanthine dehydrogenase gene by RT-PCR. The 11 primer pairs used for the amplification are shown in Table I. Within the entire coding region, only two base changes were identified for subject 1 when compared with the sequence reported previously (7). Thus, a $\mathrm{C}$ to $\mathrm{T}$ base change at nucleotide position 682 and a $\mathrm{G}$ to $\mathrm{C}$ change at 3449 (data not shown) were found (7). The former nucleotide substitution should generate a nonsense substitution from CGA (Arg) to TGA (Ter) at codon 228, while the latter should cause a missense base change from CGC (Arg) to CCC (Pro) at codon 1150. The latter base replacement was also observed in the sequence of human xanthine dehydrogenase recently reported (18).
cDNA for xanthine dehydrogenase was also synthesized by RT-PCR, using total RNA obtained from B lymphoblast cell lines from subject 3 . The amplification of cDNA from B cell lines was possible only during the early phase after the establishment of the cell lines. These data probably reflect the transient synthesis of minimal amounts of mRNA for xanthine dehydrogenase in this type of cell. Sequencing of cDNA from subject 3 verified the fact that he also carried the same nonsense mutation CGA (Arg) to TGA (Ter) at codon 228. Repetitive sequencing experiments showed that his cDNA had only the mutational but not normal sequence at this nucleotide position. On the other hand, cDNA from subject 4 did not carry the mutation at nucleotide 682 but had a deletion of $C$ at nucleotide 2567 (data not shown). This single nucleotide deletion should cause a frame shift and generate a termination codon from nucleotide 2783 . The $\mathrm{G}$ to $\mathrm{C}$ change at 3449 was also present in the sequence of cDNA from subject 4 (data not shown).

SSCP analysis after PCR amplification of genomic DNA. Genomic DNA from subjects 1-4, the father and the mother of subjects 1 and 2, and two control subjects was submitted to the PCR procedure followed by the SSCP analysis as described in Methods. When the electrophoresis was performed at $20^{\circ} \mathrm{C}$, the separation of the mutant and normal sequence was not successful. However, when the temperature was raised to $37^{\circ} \mathrm{C}$, the mutant sequence was clearly separated from the normal sequence. As in Fig. 3, subjects 1 and 2 were shown to be homozygous concerning the nonsense mutation at codon 228 , while both the father and the mother of subjects 1 and 2 were heterozygous. Although the sequencing of cDNA from subject 3 showed that it contained only the mutant sequence, the genomic DNA from the same subject indicated that he was in fact heterozygous as to this mutation. The genomic DNA from subject 4 had no alleles with the nonsense mutation at codon 228 (Fig. 3).

Analysis of genomic DNA at nucleotide 2567. Genomic DNA from subject 4 was amplified as described in Methods for the analysis of the single nucleotide deletion at nucleotide 2567. The direct sequencing of the amplified genomic DNA revealed that subject 4 had the deletion of $\mathrm{C}$ at nucleotide 2567 as a homozygous state (data not shown).

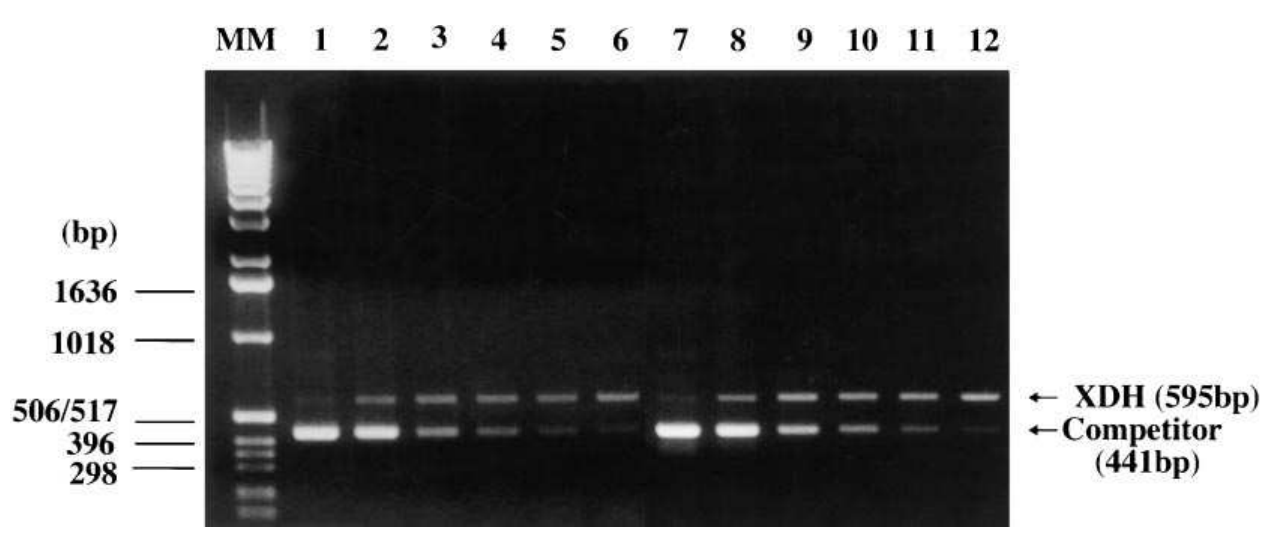

Figure 2. Quantification of xanthine dehydrogenase mRNA. $0.5 \mu \mathrm{g}$ of total RNA from the duodenal mucosa of the control subject (lanes 1-6) or subject 1 (lanes 7-12) was used as test templates for cDNA synthesis. Procedures for the competitive RT-PCR were as described in Methods. The final PCR products were subjected to $1 \%$ agarose gel electrophoresis and stained with ethidium bromide. The amount of the competitor template added per tube was 0.2 amol (lanes 1 and 7), $2.0 \times 10^{-2}$ amol (lanes 2 and 8 ), $1.0 \times$ $10^{-2}$ amol (lanes 3 and 9), $5.0 \times 10^{-3}$ amol (lanes 4 and 10), $2.5 \times 10^{-3}$ amol (lanes 5 and 11), or $1.25 \times$ $10^{-3}$ amol (lanes 6 and 12). XDH, xanthine dehydrogenase. 


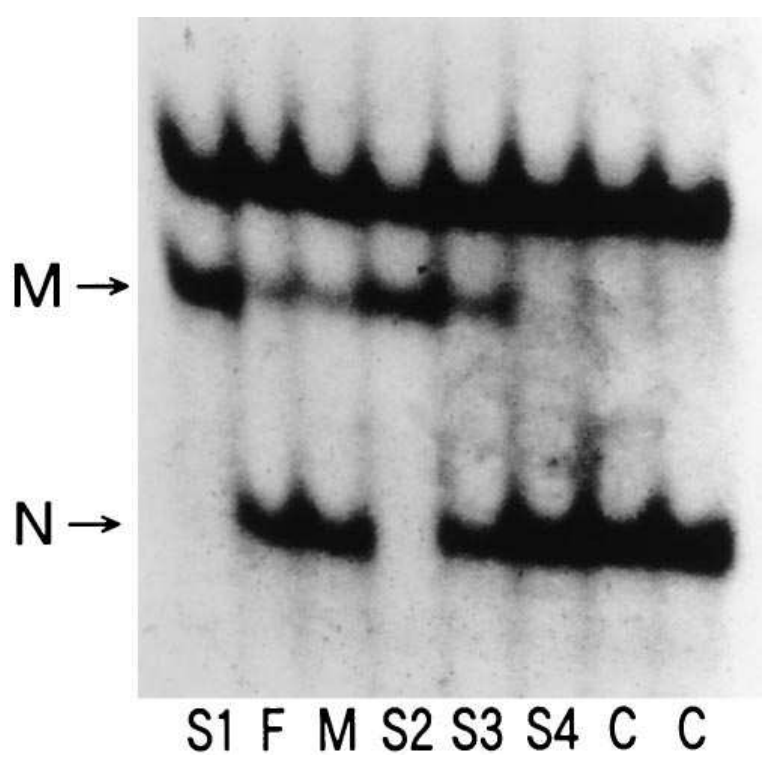

Figure 3. Genomic DNA was extracted from either peripheral blood mononuclear cells or B cell lines from subject $1(S 1)$, subject $2(S 2)$, the father $(F)$ and the mother $(M)$ of subjects 1 and 2, subject $3(S 3)$, subject $4(S 4)$, and two control subjects $(C)$. The genomic DNA was submitted to the PCR-SSCP procedure and the gel was stained with silver as described in Methods. Mutant specific $(M)$ and normal specific $(N)$ bands are indicated with arrows. Note that a single double strand DNA fragment should generate two bands in this system, one corresponding to the sense and the other to the antisense sequence.

Analysis of genomic DNA at nucleotide 3449. Genomic DNA from subjects 1-4 and six control subjects was amplified as described in Methods for the analysis of the base substitution at nucleotide 3449. Direct sequencing of the amplified genomic DNA showed that all 10 subjects were homozygous for $\mathrm{C}$ at nucleotide 3449 (data not shown). In addition, whether the nucleotide position at 3449 was $\mathrm{G}$ could be determined by the digestion of the amplified DNA with Aci I restriction en- zyme. Results also showed that none of the 10 subjects, including the 4 subjects with xanthinuria, had $\mathrm{G}$ at nucleotide 3449 because DNA from all the individuals was resistant to the cleavage (Fig. 4). Therefore, $\mathrm{G}$ at nucleotide 3449 seems to be either a rare polymorphism, a nucleotide change generated during the establishment of the cDNA library, or a sequencing error.

\section{Discussion}

In the present investigation, we identified a $\mathrm{C}$ to $\mathrm{T}$ base substitution at nucleotide 682 (nucleotide number in cDNA) and a deletion of $\mathrm{C}$ at nucleotide 2567 . The former mutation should cause a CGA (Arg) to TGA (Ter) nonsense mutation at codon 228 , while the latter mutation should cause a frameshift from codon 856 , and a termination codon is encountered at codon 928. Human xanthine dehydrogenase is a large molecule consisting of 1333 amino acids (7). Mapping of the functions on xanthine dehydrogenase was performed for three peptide domains generated by the protein cleavage (2). The $\mathrm{NH}_{2}$-terminal $20-\mathrm{kD}$ domain includes a $2 \mathrm{Fe} / 2 \mathrm{~S}$ nonheme iron binding site, while the adjacent $40-\mathrm{kD}$ and the $\mathrm{COOH}$-terminal $85-\mathrm{kD}$ domains include flavin binding and molybdenum cofactor binding domains, respectively (2). Recently, it was reported that many segments in xanthine dehydrogenase protein contact molybdenum cofactor (19). Both nonsense and deletion mutations found here may cause the cells to synthesize the truncated peptides. However, even if they are synthesized, normal functions are not likely to be retained. Flavin and molybdenum cofactor binding sites would be missing in the xanthine dehydrogenase peptide of subject 1 and the peptide of subject 4 would lack molybdenum cofactor binding sites.

The results of the Western blot and quantitative RT-PCR analyses were consistent with the mutation we identified. Since subjects 1 and 4 were homozygous for the nonsense and deletion mutations, respectively, all mRNA synthesized in each subject should possess a single defect. The nonsense mutation in mRNA would cause a failure in synthesizing mature protein detectable by the Western blot method. Although some re-

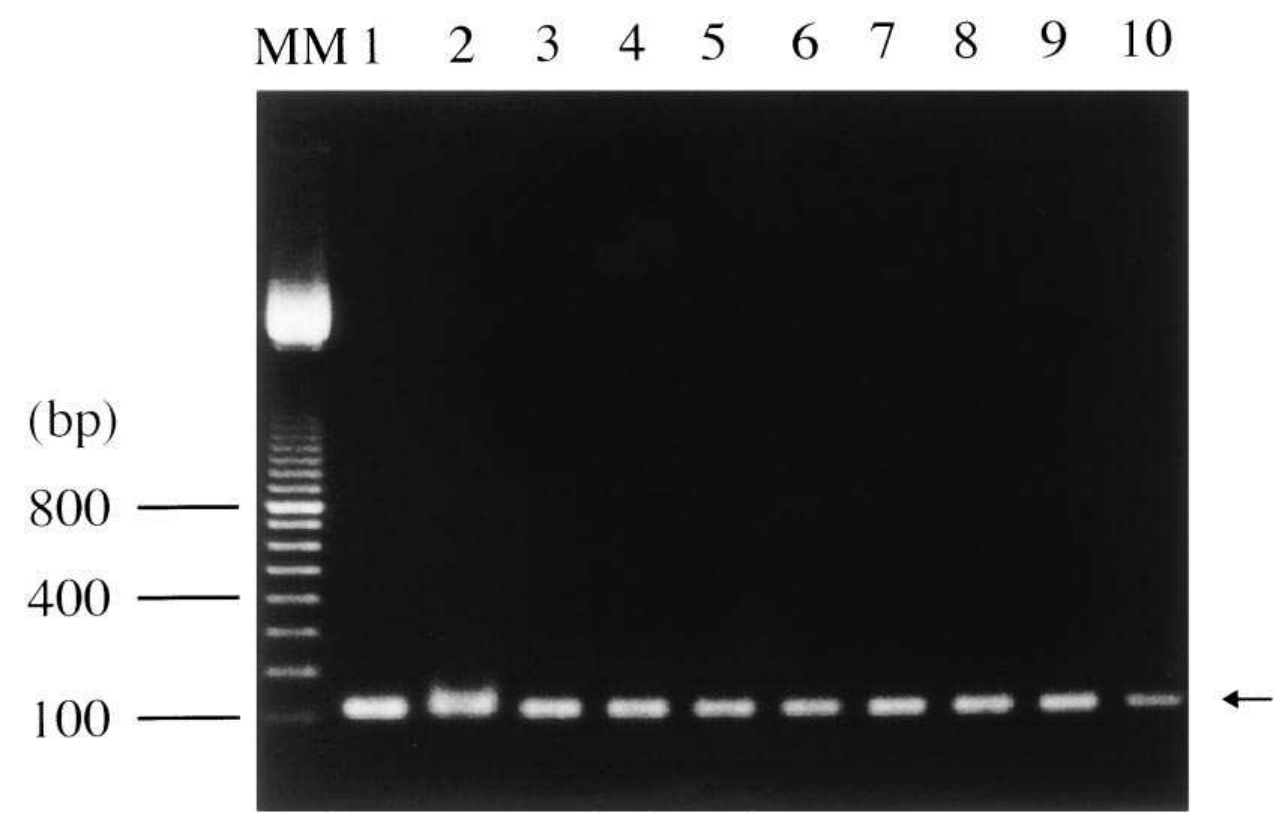

Figure 4. Analysis of genomic DNA at nucleotide 3449. Genomic DNA was extracted from subjects 1-4 (lanes 1-4) and six control subjects (lanes 5-10). Thereafter, a part of the sequence including the nucleotide 3449 was amplified as described in Methods. The amplified DNA was digested with Aci I under the conditions recommended by the supplier and submitted to agarose gel electrophoresis. The arrow indicates the bands at 115 bp corresponding to the uncleaved xanthine dehydrogenase DNA segment. 
ports described decreases in the amounts of mRNA by nonsense mutations (20), they probably reflected the relative instability of mRNA. It is not surprising that such decreases in the amounts of mRNA are not found in other cases with nonsense and deletion mutations. Therefore, our data regarding the enzyme protein and mRNA are essentially what would be expected from the nonsense and deletion mutations we found.

By the analysis of the genomic DNA, the genotypes of the four subjects were determined. Both subjects 1 and 2 were homozygous for the nonsense mutation at codon 228 , while subject 3 was a compound heterozygote. One of the alleles in subject 3 had the nonsense mutation while the other mutation remains to be identified. Since the codon 228 nonsense mutation was exclusively observed in the cDNA from his B cell line, the analysis of the entire genomic DNA is likely to be required to identify the other mutation. Subject 4 was found to be homozygous for the deletion mutation in both of the alleles. Since subjects 1,2 , and 4 had classical xanthinuria type I (Table I), the genetic defects in the xanthine dehydrogenase gene were confirmed to cause classical xanthinuria type I.

Although it is not surprising that we identified the same mutation in subjects 1 and 2, the presence of the same mutation in subject 3 is of interest. Codon 228 in the human xanthine dehydrogenase gene may be a hot spot for mutation since $\mathrm{C}$ in the $\mathrm{CpG}$ duplet is often methylated in the germline, and the deamination of methyl cytosine would convert the base to thymine (21). Therefore, the same mutation found in the family of subjects 1 and 2 and in subject 3 may reflect recurrent germline mutations at the mutational hot spot. Alternatively, the nonsense base substitution found in the two separate families may have originated from a single mutation. The latter possibility cannot be excluded since, in some autosomal recessive diseases, the same mutation found in separate families in an ethnic group were derived from a single ancestor gene (22-24).

Identification of mutations in the xanthine dehydrogenase gene in classical xanthinuria type I provides a first molecular basis to the complicated classification of xanthinuria. Thus, although the primary causes of classical xanthinuria type II and molybdenum cofactor deficiency are still to be investigated, the cause of classical xanthinuria type I was confirmed to be located in the xanthine dehydrogenase gene. It is of interest to note that defects in the sulfuration of desulfo molybdenum hydroxylases have been hypothesized as the underlying mechanism in type II xanthinuria, since a similar defect is present in Drosophila melanogaster (25). In mammals, however, it is still unclear how a molybdenum cofactor of xanthine dehydrogenase and aldehyde oxidase is converted from the desulfo form to the sulfo form, or how the cofactor is introduced into the apo enzymes. Further molecular studies on individuals with classical xanthinuria type II and molybdenum cofactor deficiency are likely to contribute to a more reliable classification of hereditary xanthinuria and the further understanding of the biochemical relationship between those enzymes.

Xanthine dehydrogenase is known to be converted to the oxidase form by the proteolytic cleavage and the oxidation of cystein residues (6). The oxidase form has been implicated as the main generator of the active oxygen species, which are considered to be pathogenic in such conditions as postischemic reperfusion tissue injury $(26,27)$, adult respiratory distress syndrome (28), and lung injury resulting from influenza virus infection $(29,30)$. Moreover, the $5^{\prime}$ flanking region of the human xanthine dehydrogenase gene contains CCAAT/enhancer binding protein (C/EBP), IL-6, and nuclear factor $-\kappa \mathrm{B}$ binding sites, consensus sequences related to inflammation and acute phase responses (31). When such physiological and pathological roles of xanthine dehydrogenase/oxidase are considered, the presence of individuals who lack the enzyme is valuable. When the above hypotheses are evaluated, one should keep in mind that there are individuals in which no generation of active oxygen species through this pathway is present. Our present study confirms that in such individuals, the ability to synthesize xanthine dehydrogenase is indeed genetically impaired.

\section{Acknowledgments}

We thank Dr. Shigeaki Muto (Department of Nephrology, Jichi Medical School, Tokyo, Japan) for supplying a blood sample from subject 3 , and Drs. Ryozo Sakuma and Toshihiro Nishina (Toranomon Hospital, Tokyo, Japan) for performing the xanthine dehydrogenase/oxidase assays. We also thank Dr. M.W. Schein (Rockville, MD) for reviewing this manuscript.

\section{References}

1. Dent, C.E., and G.R. Philport. 1954. Xanthinuria, an inborn error (or deviation) of metabolism. Lancet. i:182-185.

2. Simmonds, H.A., S. Reiter, and T. Nishino. 1995. Hereditary xanthinuria. In The Metabolic Basis of Inherited Disease. 7th ed. C.R. Scriver, A.L. Beaudet, W.S. Sly, and D. Valle, editors. McGraw-Hill, Inc., New York. 1781-1797.

3. Reiter, S., H.A. Simmonds, N. Zollner, S.L. Braun, and M. Knedel. 1990. Demonstration of a combined deficiency of xanthine oxidase and aldehyde oxidase in xanthinuric patients not forming oxypurinol. Clin. Chim. Acta. 187:221-234.

4. Jonson, J.L., and S.K. Wadman. 1995. Molybdenum cofactor deficiency and isolated sulfite oxidase deficiency. In The Metabolic Basis of Inherited Disease. 7th ed. C.R. Scriver, A.L. Beaudet, W.S. Sly, and D. Valle, editors. McGraw-Hill, Inc., New York. 2271-2283.

5. Harkness, R.A., G.M. McCreanor, D. Simpson, and I.R. MacFadyen 1986. Pregnancy in and incidence of xanthine oxidase deficiency. J. Inherited Metab. Dis. 9:407-408.

6. Amaya, Y., K. Yamazaki, M. Sato, K. Noda, T. Nishino, and T. Nishino. 1990. Proteolytic conversion of xanthine dehydrogenase from the NAD-dependent type to the $\mathrm{O}_{2}$-dependent type. J. Biol. Chem. 265:14170-14175.

7. Ichida, K., Y. Amaya, K. Noda, S. Minoshima, T. Hosoya, O. Sakai, N. Shimizu, and T. Nishino. 1993. Cloning of the cDNA encoding human xanthine dehydrogenase (oxidase): structural analysis of the protein and chromosomal location of the gene. Gene. 133:279-284.

8. Minoshima, S., Y. Wang, K. Ichida, N. Shimizu, T. Nishino, and N. Shimizu. 1995. Mapping of the gene for human xanthine dehydrogenase (oxidase) (XDH) to the band p23 of chromosome 2. Cytogenet. Cell Genet. 68:52-53.

9. Wright, R.M., G.M. Vaitaitis, C.M. Wilson, T.B. Repine, L.S. Terada, and J.E. Repine. 1993. cDNA cloning, characterization, and tissue-specific expression of human xanthine dehydrogenase/xanthine oxidase. Proc. Natl. Acad. Sci. USA. 90:10690-10694.

10. Turner, N.A., W.A. Doyle, A.M. Ventom, and R.C. Bray. 1995. Properties of rabbit liver aldehyde oxidase and the relationship of the enzyme to xanthine oxidase and dehydrogenase. Eur. J. Biochem. 232:646-657.

11. Oono, S., S. Muto, T. Nishina, R. Sakuma, H. Yamanaka, K. Nishioka, K. Tabei, and Y. Asano. 1992. A case of hereditary xanthinuria with chronic renal failure due to diabetic nephropathy. Intern. Med. (Tokyo). 70:192-195.

12. Kono, S., T. Hosoya, K. Kodama, A. Matsumoto, Y. Oda, Y. Ogura, S. Sakai, and T. Miyahara. 1984. Two cases of xanthinuria in brothers. Naikagakkaizasshi. 73:33-38.

13. Kojima, T., T. Nishina, M. Kitamura, T. Hosoya, and K. Nishioka. 1984. Biochemical studies on the purine metabolism of four cases with hereditary xanthinuria. Clin. Chim. Acta. 137:189-198.

14. Ichikawa, M., T. Nishino, T. Nishino, and A. Ichikawa. 1992. Subcellular localization of xanthine oxidase in rat hepatocytes: high-resolution immunoelectron microscopic study combined with biochemical analysis. J. Histochem. Cytochem. 40:1097-1103.

15. Saiki, R.K., D.H. Gelfand, S. Stoffel, S.J. Sharf, R. Higuchi, G.T. Horn, K.B. Mullis, and H.A. Erlich. 1988. Primer-direct enzymatic amplification of DNA with a thermostable DNA polymerase. Science (Wash. DC). 239:487-491.

16. Terai, C., M. Hakoda, H. Yamanaka, N. Kamatani, M. Okai, F. Takahashi, and S. Kashiwazaki. 1995. Adenine phosphoribosyltransferase deficiency identified by urinary sediment analysis: cellular and molecular confirmation. 
Clin. Genet. 48:246-250.

17. Hille, R., and T. Nishino. 1995. Xanthine oxidase and xanthine dehydrogenase. FASEB J. 9:995-1003.

18. Saksela, M., and K.O. Raivio. 1996. Cloning and expression in vitro of human xanthine dehydrogenase/oxidase. Biochem. J. 315:235-239.

19. Romao, M.J., M. Archer, I. Moura, J.J.G. Moura, J. LeGall, R. Engh, M. Schneider, P. Hof, and R. Huber. 1995. Crystal structure of the xanthine oxidase-related aldehyde oxido-reductase from D. gigas. Science (Wash. DC). 270:1170-1176.

20. Brawerman, G. 1989. mRNA decay: finding the right targets. Cell. 57:9-10.

21. Coulondre, C., J.H. Miller, P.J. Farabaugh, and W. Gilbert. 1978. Molecular basis of base substitution hotspots in Escherichia coli. Nature (Lond.). 274:775-780.

22. Kamatani, N., M. Hakoda, S. Otsuka, H. Yoshikawa, and S. Kashiwazaki. 1992. Only three mutations account for almost all defective alleles causing adenine phosphoribosyltransferase deficiency in Japanese patients. J. Clin. Invest. 90:131-136.

23. Satokata, I., K. Tanaka, and Y. Okada. 1992. Molecular basis of group A xeroderma pigmentosum: a missense mutation and two deletions located in a zinc finger consensus sequence of the XPAC gene. Hum. Genet. 88:603-607.

24. Simmonds, H.A., A.S. Sahota, and K.J. Van Acker. 1995. Adenine phosphoribosyltransferase deficiency and 2,8-dihydroxyadenine lithiasis. In
The Metabolic Basis of Inherited Disease. 7th ed. C.R. Scriver, A.L. Beaudet, W.S. Sly, and D. Valle, editors. McGraw-Hill Inc., New York. 1707-1724.

25. Wahl, R.C., C.K. Warner, V. Finnerty, and K.V. Rajagopalan. 1982. Drosophila melanogaster ma-1 mutants are defective in the sulfuration of desulfo Mo hydroxylases. J. Biol. Chem. 257:3958-3962.

26. MacGowan, S.W., M.C. Regan, C. Malone, O. Sharkey, L. Young, T.F Gorey, and A.E. Wood. 1995. Superoxide radical and xanthine oxidoreductase activity in the human heart during cardiac operations. Ann. Thorac. Surg. 60: 1289-1293.

27. McCord, J.M. 1985. Oxygen-derived free radicals in post-ischemic tissue injury. N. Engl. J. Med. 312:159-163.

28. Grum, C.M., R.A. Ragsdale, L.H. Ketai, and R.H. Simon. 1987. Plasma xanthine oxidase activity in patients with ARDS. J. Crit. Care. 2:22-26.

29. Oda, T., T. Akaike, T. Hamamoto, F. Suzuki, T. Hirano, and H. Maeda. 1989. Oxygen radicals in influenza-induced pathogenesis and treatment with pyran polymer-conjugated SOD. Science (Wash. DC). 244:974-976.

30. Akaike, T., M. Ando, T. Oda, T. Doi, S. Ijiri, S. Araki, and H. Maeda. 1990. Dependence on $\mathrm{O}_{2}$-generation by xanthine oxidase of pathogenesis of influenza virus infection in mice. J. Clin. Invest. 85:739-745.

31. Xu, P., T.P. Huecksteadt, and J.R. Hoidal. 1996. Molecular cloning and characterization of the human xanthine dehydrogenase gene (XDH). Genomics. 34:173-180. 